\title{
Testing equipment for experimental analysis of mechanical properties of textile materials
}

\author{
Martin Bílek $^{1 \mathrm{a}}$, Šimon Kovár ${ }^{1}$, Eva Moučková ${ }^{2}$ and Petr Tumajer ${ }^{2}$ \\ ${ }^{1}$ Technical University of Liberec, Dept. of Textile Machine Design, Studentská 2, 46117 Liberec 1, Czech Rep. \\ ${ }^{2}$ Technical University of Liberec, Department of Textile Technologies, Studentská 2, 46117 Liberec 1, Czech Rep.
}

\begin{abstract}
The regular equipment for testing of textile materials does not facilitate the elongation of threads at a frequency corresponding to the frequency of loading during technological process, and it does not allow for clamping a thread of the corresponding length. In the Technical University Liberec there has been built a testing equipment for experimental analysis of deformation characteristics of textile materials during cyclical loading at a wide range of frequencies (VibTex), and there has been devised the methodology for realisation of experimental measuring and processing of the measured data. The submitted paper explains this experimental equipment for simulation of thread loading, which has been created in the Technical University Liberec for analysis of behaviour of textile materials at high loading frequencies.
\end{abstract}

\section{Introduction}

The textile materials and products made of these materials are exposed to varied load regimes. The load regime of finished products made of textile materials is determined by the manner of their use; meanwhile the load regime of textile materials during their processing is determined by technological process. The deformation properties of finished textile products often determine and limit the use of these products in certain areas [1]. The deformation properties of textile materials influence the technological process itself, as well as the quality of the finished product. A typical example is technological process of weaving. In the second half of past century, the output of weaving machines was increasing considerably. Around the turn of the century, this trend has changed, i.e. the outputs of weaving machines are stagnating or decreasing. One of possible reasons of this standstill in the increase of outputs can be deformation properties and behaviour of textile materials in the weaving process. During weaving, the textile material (thread, fabric) is loaded cyclically, at a relatively high frequency. Some products made of textile materials are exposed to cyclical or dynamic load in their use, too, e.g. safety belts, straps, ropes, liquid and air filters, artificial tendons etc.

The dynamic methods of determining deformation and damping properties of the material utilise cyclical deformations of the sinus course primarily. The regular equipment for testing of textile materials (dynamometers) does not facilitate the elongation of threads at a frequency corresponding to the frequency of loading during

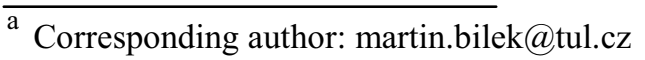

technological process, and it does not allow for clamping a thread of the corresponding length. In the Technical University Liberec there has been built a testing equipment VibTex for experimental analysis of deformation characteristics of textile materials during cyclical loading at a wide range of frequencies, and there has been devised the methodology for realisation of experimental measuring and processing of the measured data. The constructed equipment allows for ascertaining deformation characteristics of both linear and flat textile objects. It allows also evaluating the energetic intensity when processing varied textile materials (for example on a weaving machine, it is possible evaluate the individual materials, as concerns the energy required for their deformation when opening the shed or during the beat-up process) [3].

\section{VibTex: special equipment for testing of textile objects}

The equipment VibTex facilitates the simulation of behaviour of textile materials and products exposed to cyclical load. The design of the equipment allows realising the tests of linear and flat textiles at a wide range of frequencies (fig. 2).

The equipment is based on an electromagnetic vibration system, consisting of the proper vibration exciter TIRAvib TV50350, an output amplifier and a doublechannelled control unit VR8500. On the vibration exciter, there is fastened an acceleration sensor, and its signal is brought to the first channel of the control unit. By means 
of the amplifier, the control unit regulates the input voltage to the vibration exciter, in order to achieve the required course of acceleration. The required course of acceleration can be entered by means of the software
VibrationVIEW, supplied with the control unit. This software is installed in a regular computer, and it communicates with the control unit by means of network cable.

Figure 1 Diagram of standard connection of the vibration system Scheme of the conventional
connection of the vibration system

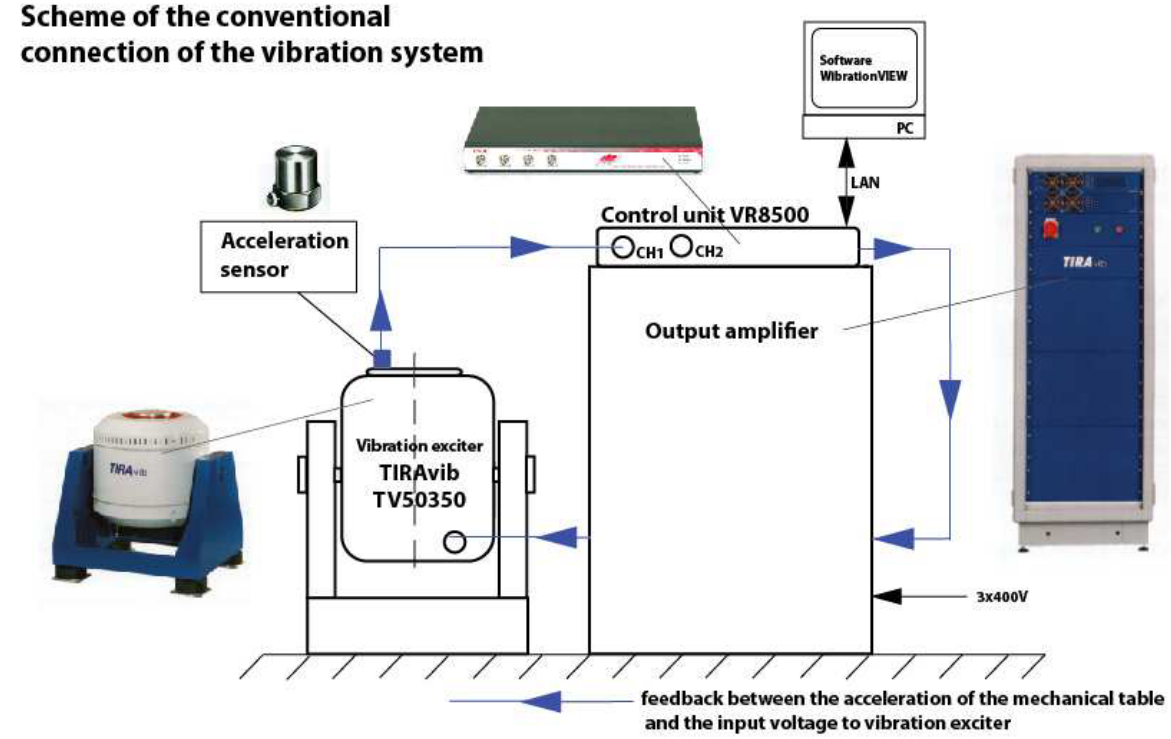

The vibration equipment in the above configuration serves primarily for testing of varied machine components that can be fastened on ,mechanical table“ of the vibration exciter (fig. 1). For the purpose of testing textile materials, the system must be adapted conveniently. In our case, the vibration exciter is employed as a control member extending the textile sample. Therefore, its axis is oriented horizontally, and upon the „mechanical table“ there is fastened the end of the tested sample and an inductance sensor of the path, measuring the elongation of the sample (the exciting function) during the test. The other end of tested sample is fastened to a fixed frame, the construction of which allows adjusting varied clamping lengths of the textile object (from $20 \mathrm{~cm}$ up to $3 \mathrm{~m}$ ). In the fixed frame there is integrated a tensiometer, which allows measuring the tensile force in the textile (the response) during the test. Furthermore, there is situated here the screw for adjusting the required value of „preloading“ in the textile sample. Clamping elements for testing both linear and flat textiles are available, too.

Figure 2. Vibration equipment VibTEX

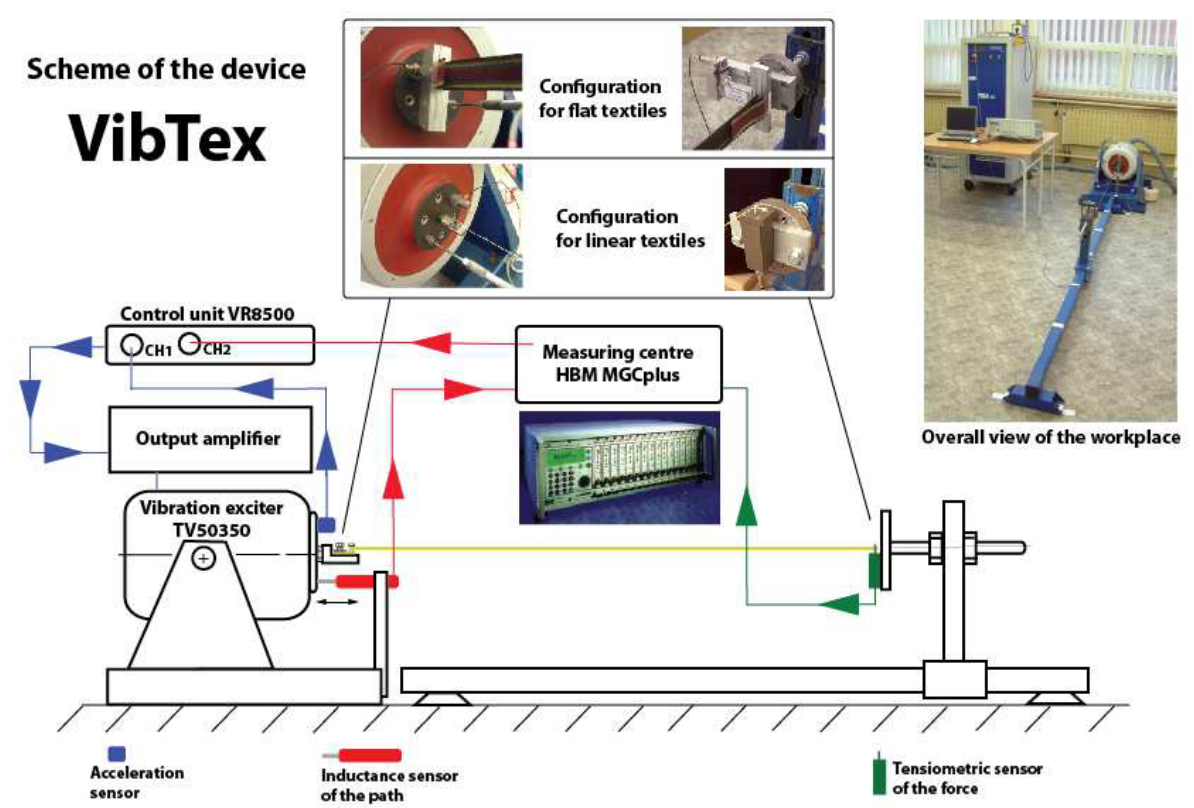


The signal coming from both the inductance and tensiometric sensors is processed by means of the measuring centre HBM MGCplus. The signal is digitized here, and the measured values are stored in an ASCII file in respective physical units. Consequently, the main output of measuring is the time dependence of the elongation (exciting function) and the tensile force (response) in the tested sample. The output connector of the board of inductance sensor is interconnected with the other channel of the control unit; therefore, the course of the deflection of „mechanical table“ (elongation of the sample) can also be visualised in the program VibrationVIEW.

The software VibrationVIEW allows realising tests with varied courses of elongation. For the formation of tests, two modules are available in the existing configuration: System Check and Field Data Replicator. During routine operation of the vibration system, the module System Check serves for checking its functionality. However, when testing textile objects, this module can be employed for harmonic elongation of the samples successfully. The user interface of this module allows for entering of the required frequency and amplitude of acceleration. At the start of the equipment VibTex, the deviation of the mechanical table goes on increasing gradually up to the required value.

The module Field Data Replicator allows for producing tests from files in varied formats. In case of the testing equipment VibTex, we make use of text files containing two columns of numerals. The first column incorporates the values determining time, and the second one contains the values of required acceleration. The text file can be generated by means of an arbitrary program (e.g. the table calculator Excel), and then exported into the module Field Data Replicator. In this way, it is possible to generate a test with any arbitrary periodical elongation of the textile sample.

The maximum achievable values of elongation (deflections of ,mechanical table“) are determined by the construction of the vibration exciter. The following figure No. 3 shows the dependence of the maximum achievable deflection on the frequency (in logarithmic co-ordinates). By means of the given vibration system, the textile sample can be elongated by the value $25 \mathrm{~mm}$ up to $10 \mathrm{~Hz}$. After that, the maximum achievable deflection decreases, and at $100 \mathrm{~Hz}$, the sample can be elongated by $4 \mathrm{~mm}$ approximately.

Figure 3. Maximum deflection

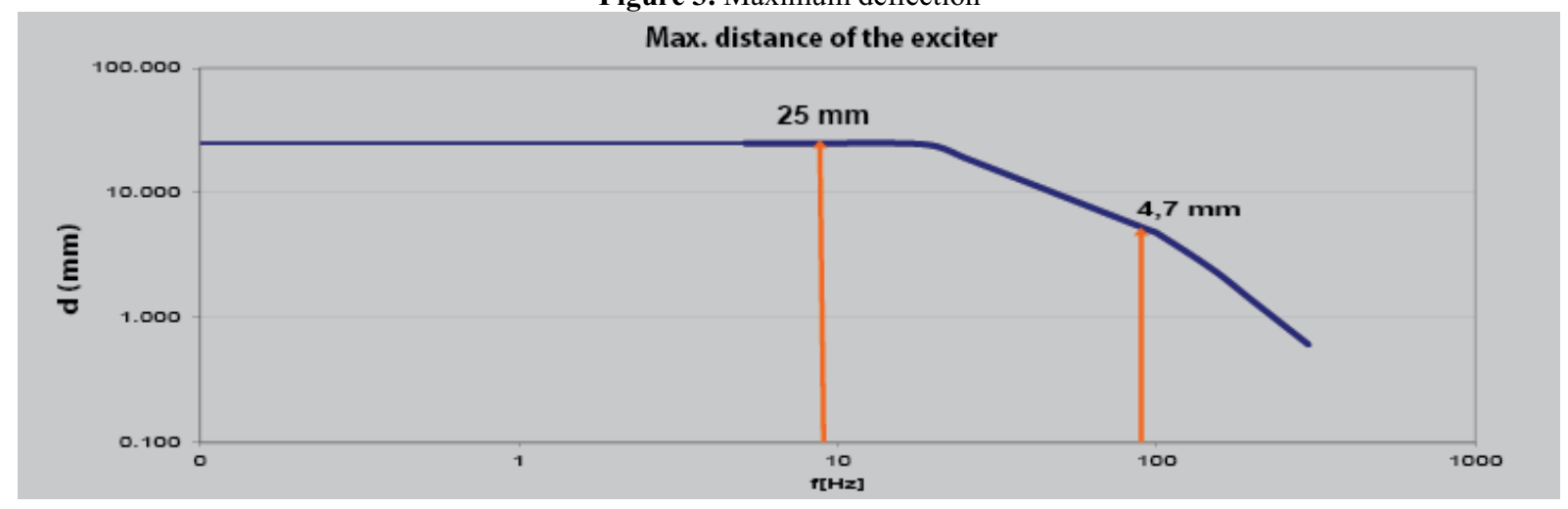

Concerning the evaluation of mechanical properties [2] of tested samples, it is necessary to record the courses of elongation (exciting function) and tensile force (response). As mentioned already above, the signals from the inductance sensor of the path and of the tensiometric sensor of the force are processed by means of the measuring centre HBM MGCplus. By means of a network cable, this centre is interconnected with the computer comprehending the service software HBM Setup Assistant. This software facilitates visualisation of measured data and their storage in text files intended for subsequent further processing by means of the evaluating software VibTex Soft.

In practice, it has come out that the employment of the inductance sensor of the path allows using the testing equipment VibTex up to the maximum frequency $40 \mathrm{~Hz}$ of the load exerted upon the sample, with the elongation of the sample of textile material $10 \mathrm{~mm}$. Once this operating frequency is exceeded, the record of the path shows instabilities due primarily to the construction of the fixture devised for clamping the inductance sensor of the path to the frame of the vibration exciter. For measuring higher loading frequencies, the inductance sensor of the path can be substituted e.g. by a contactless laser velocity scanner Brüel \& Kjær 8338. This laser vibration meter serves for contactless and very fast measuring of vibration velocities. The employed scanner Brüel \& Kjær 8338 operates at a distance up to 3 meters from the scanned object.

The basic diagram of measuring has been complemented with a circuit with the record by means of the vibration meter Brüel \& Kjær 8338. To the first channel of the measuring centre HBM MGCplus there is brought the signal from the acceleration sensor, and to the second channel, the signal from the inductance sensor of the path. To the third channel, there is brought the signal of velocity from the laser vibration meter. The fig. 4 shows the record of courses of all the three quantities.

The comparison of the courses of the path, velocity and acceleration of harmonic motion confirms a high accordance of the data obtained experimentally and of theoretic courses. At the same time, there is determined

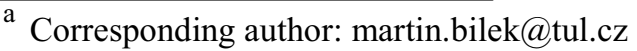


the minimum deflection of amplitudes of the deflection, velocity and acceleration in the whole interval of employed exciting frequencies, in comparison with parameters entered by means of the system VibrationView. It is also possible to state a high stability in the adjustment of the exciting frequency. On the basis of this fact, the actual course of elongation of textile material by means of the testing equipment VibTex can be considered ideally harmonic.

Figure 4. Sensing of velocity by means of laser contactless scanner

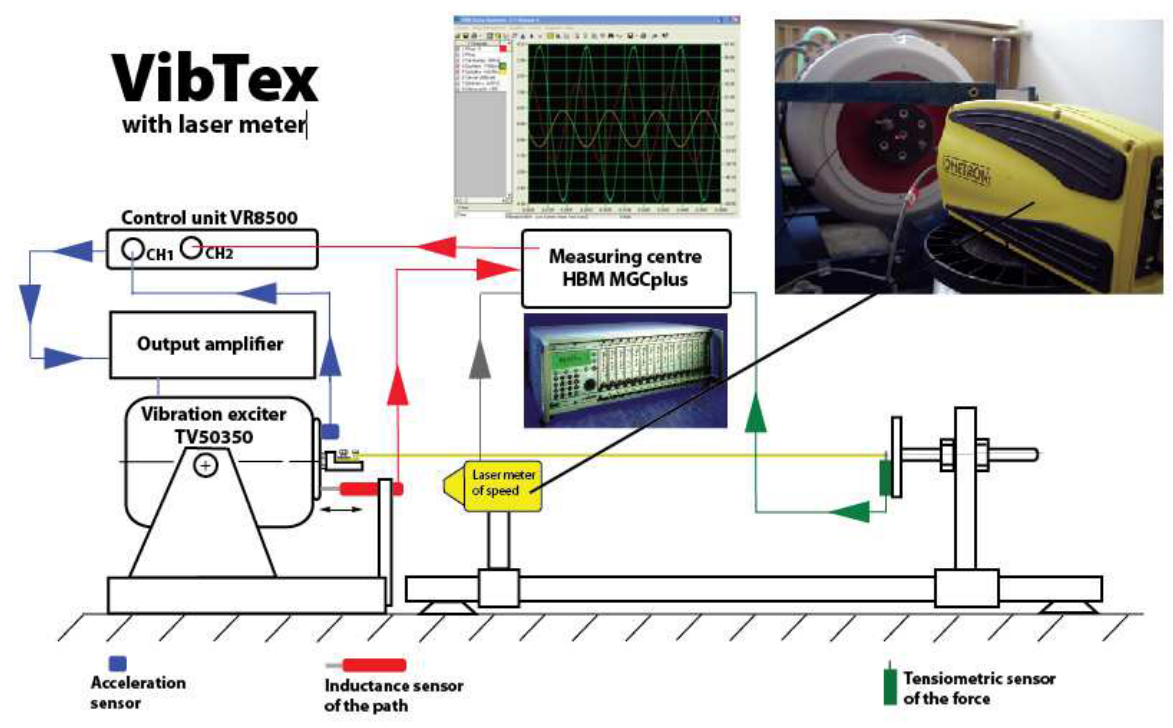

Figure 5. Example of ascertained dependence of the tensile force in the thread upon its elongation at the loading frequency $10 \mathrm{~Hz}$ with varied values of pre-loading

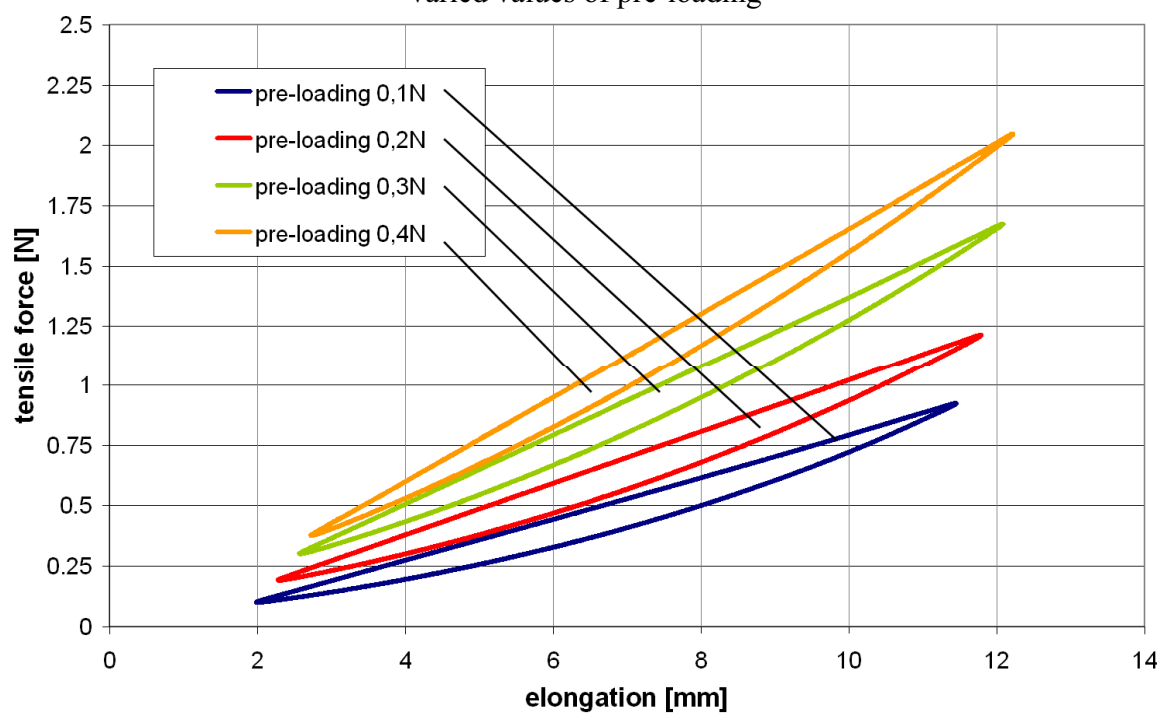

\section{VibTex: special equipment for testing of textile objects}

The dynamic methods of determining deformation and damping properties of the material utilise cyclical deformations of the sinus course primarily. The body is deformed by the effect of the load. All the work consumed in the deformation of an ideally elastic body is accumulated in it in form of potential energy, which can be recovered on the return to not deformed state. Thanks to viscous properties of material, a part of the work put into the system is converted in heat irreversibly. There exists a number of ways how to express the measure of energy dissipation [5].

If the harmonic motion is steadied, the said dependence can be expressed by a diagram of dependence of the sum of restoring and damping forces of the spring upon the amplitude of the deflection. In case of a visco-elastic substance, this diagram depicts an elliptic shape of the hysteresis loop. An example of obtained dependencies is given in the fig. 5 . 


\section{Conclusion}

As the effected measuring has proven, the testing equipment can be employed for ascertaining the basic mechanical quantities of textile materials with success. It is not problematic to ascertain the forces acting in textile materials. On the contrary, the determination of the actual position of mechanical table of the vibration exciter becomes problematic with this equipment at higher frequencies of loading of the tested sample. This problem can be resolved by employment of a contactless laser vibration scanner.

The testing equipment VibTex allows realising repeatable measuring of deformation properties of textile materials in an ideally harmonic course [4]. On the basic of this measuring, important pieces of information about the examined material can be obtained.

Acknowledgement: This publication was written at the Technical University of Liberec, Faculty of Mechanical Engineering with the support of the Institutional Endowment for the Long Term Conceptual Development of Research Institutes, as provided by the Ministry of Education, Youth and Sports of the Czech Republic in the year 2015 .

\section{References}

1. Nosek S. Straining of various linear textile bodies in generalized drawing fields, mainly in warps on looms, Conference Textile Science, TU- Liberec, Czech Republic, 1998, pp. 125-138

2. Bílek, M., Brotz, I., Mrázek, J., Tumajer, P.: Mechanical properties of a textile material: Harmonization of mechanic impedances of the weaving machine and the textile material . Buletinul Institutului Politehnic Din Iasi, Mechanica Aplicata 2005. s. 177-184, Iasin, Romania,

3. Bílek, M., Kovář, Š., Mrázek, J., Tumajer, P.: Versucheinrichtung zur Analysierung des Dynamischen Verhaltens des Fadens. XV. Wissenschaftliches symposium TU Liberec - TU Dresden. s. 141-146, Liberec 2005, Czech Republic,

4. Tumajer P., Ursíny P., Bílek M., Moučková E.; Research Methods for the Dynamic Properties of Textiles. FIBRES \& TEXTILES in Eastern Europe 2011, Vol. 19, No. 5 (88) pp. 33-39.

5. Morton, W. E.; Hearle, J. W. S.: Physical properties of textile fibres, Manchester \& London, The Textile Institute, Butterworths, 1962.

6. Tumajer P., Ursíny P., Bílek M., Moučková E.; Use of the Vibtex vibration system for testing textiles, Autex Research Journal 2011, (11), No 2, pp. 47-53, ISSN 1470-9589

7. Snycerski, M.: The pulsator - a generator of cyclic longitudinal impact loads to simulate weaving conditions for warp yarn, Fibres and Textiles in Eastern Europe, 5 (4), pp. 65-67, ISSN 12303666, 1997.

8. Vlasenko, V., Kovtun, S., Arabuli, A., Bereznenko, S.: Application of the longitudinal resonance vibration method for an investigation of a textile's visco-elastic properties, Vlakna a Textil, 14 (2), pp. 11-14. ISSN 13350617, 2007. 